Ambiente \& Água - An Interdisciplinary Journal of Applied Science
ISSN 1980-993X - doi:10.4136/1980-993X
www.ambi-agua.net
E-mail: ambi-agua@agro.unitau.br

\title{
Caracterização morfométrica da sub-bacia do rio Poxim-Açu, Sergipe, Brasil
}

\author{
doi: 10.4136/ambi-agua.1289
}

Received: 28 Jan. 2014; Accepted: 28 Mar. 2014

\author{
Ricardo Monteiro Rocha ${ }^{1^{*}}$; Ariovaldo Antonio Tadeu Lucas ${ }^{2}$; \\ Carlos Alberto Prata de Almeida ${ }^{2}$; Edson Leal Menezes Neto ${ }^{1}$; \\ Antenor de Oliveira Aguiar Netto 2 \\ ${ }^{1}$ Instituto Federal de Sergipe (IFS), Aracaju, SE, Brasil \\ ${ }^{2}$ Universidade Federal de Sergipe (UFS), São Cristóvão, SE, Brasil \\ *Autor correspondente: e-mail: ricardomonteiro2003@globo.com, \\ aatlucas@gmail.com, carlos.prata@gmail.com, edsonmene@gmail.com, \\ antenor.ufs@gmail.com
}

\section{RESUMO}

A caracterização morfométrica de uma bacia hidrográfica é um dos principais procedimentos executados em análises hidrológicas e ambientais para o entendimento de suas dinâmicas local e regional e apoiar o gerenciamento dos recursos hídricos. Este trabalho analisou as variáveis morfométricas da sub-bacia hidrográfica do rio Poxim-Açu, afluente do rio Poxim que contribui por aproximadamente $30 \%$ do abastecimento da capital sergipana. Para o Modelo Digital de Elevação (MDE) foram utilizados dados do SRTM (Shuttle Radar Topography Mission), compatíveis com a escala 1:250.000, disponibilizados pela Embrapa Monitoramento por Satélite, carta de articulação do IBGE SC-24-Z-B. Demais dados foram obtidos a partir do Atlas Digital dos Recursos Hídricos de Sergipe, processados em Sistemas de Informação Geográfica (SIG), o QGIS 1.6 e o ArcGIS 10.1 com extensões Spatial Analist e ArcHidro. Os resultados obtidos permitirão estudos ambientais mais acurados sobre esta bacia hidrográfica. Verificou-se que a sub-bacia possui uma área de $128 \mathrm{~km}^{2}$, índice de sinuosidade de $10 \%$, hierarquia fluvial de $4^{\mathrm{a}}$ ordem e coeficiente de compacidade de 1,76. Com forma alongada, é praticamente reta e com baixa tendência a picos de inundações.

Palavras-chave: morfometria, gestão de recursos hídricos, manejo de bacias, SIG.

\section{Morphometric characterization of the Poxim-Açu River sub-basin, Sergipe, Brazil}

\section{ABSTRACT}

Watershed morphometric characterization is one of the most used procedures in hydrological and environmental analysis, with the purpose of understanding local and regional dynamics to support water resource management. This paper analyzed the morphometric variables of the Poxim-Açu River sub-basin, affluent of the Poxim River, which contributes with approximately $30 \%$ of the water supply of the capital of Sergipe. We used SRTM (Shuttle Radar Topography Mission) data for the Digital Elevation Model (DEM), with the scale of 1:250,000, provided by Embrapa Satellite Monitoring and the IBGE 
topographic chart SC-24-Z-B. Other data were obtained from the Digital Atlas of Water Resources of Sergipe, which were processed in Geographic Information Systems (GIS), as the QGIS 1.6 and ArcGIS 10.1 with Spatial Analyst and ArcHidro extensions. Results will support environmental studies of this watershed. We found that the sub-basin has an area of $128 \mathrm{~km}^{2}$, sinuosity index of $10 \%$, fluvial hierarchy of the $4^{\text {th }}$ order, and a compactness coefficient of 1.76. It is practically straight with an elongated shape and a low tendency to have peaks of floods.

Keywords: morphometry, water resources management, watershed management, GIS.

\section{INTRODUÇÃO}

A escassez qualitativa e quantitativa da água está associada, historicamente, a modelos de desenvolvimento baseados na utilização irracional dos recursos naturais. Os conflitos intensificados em seus usos múltiplos motivaram reações e busca de soluções visando à compatibilização entre exploração econômica e utilização racional dos estoques ambientais. (Magalhães Júnior e Cordeiro Netto, 2003). Como recurso natural de grandeza biológica e química, que interage com os fatores edafoclimáticos, configura a diversificação dos biomas, das formas geológicas, e das mudanças climáticas.

O estudo em áreas de bacias hidrográficas urbanas e rurais é imprescindível quando se busca o equilíbrio entre a exploração de recursos naturais e a sustentabilidade ambiental. $\mathrm{O}$ processo evolutivo de seu uso manifesta-se de maneira desordenada, impulsionado pelo crescimento populacional acelerado, expansão das áreas agrícolas e intensa urbanização. (Vasco et al., 2011).

Estudos morfométricos têm sua base a partir da análise de vazões. Morisawa (1958) observou que a vazão pode ser expressa como uma função geral da geomorfologia de uma sub-bacia. A afirmação é ratificada nos estudos de Jain e Sinha (2003) e Ifabiyi (2011), ao relatarem que as características geomorfológicas de uma bacia desempenham papel-chave no controle hidrológico de bacias.

A compreensão do comportamento hídrico e o desenvolvimento da gestão de recursos hídricos, levando-se em conta suas relações antrópicas, econômicas e socioambientais, têm sido uma questão relevante para os estudos de sustentabilidade. A caracterização morfométrica de uma bacia hidrográfica é um dos principais procedimentos executados em análises hidrológicas e ambientais, tendo como objetivo elucidar questões sobre o entendimento das suas dinâmicas local e regional, apoiando o gerenciamento dos recursos hídricos (Magesh et al., 2010; Santos et al., 2012; Ferrari et al., 2013; Guedes e Silva, 2012).

A utilização dos mananciais hídricos requer estudos sistemáticos que subsidiem a elaboração de planos que visem minimizar ações antrópicas através de estratégias de gerenciamento sobre as bacias hidrográficas. Amparadas como unidades de planejamento conforme a Lei $\mathrm{n}^{\circ} 9.433$ de 08 de janeiro de 1997, as bacias hidrográficas são unidades territoriais para a implementação da Política Nacional de Recursos Hídricos e atuação do Sistema Nacional de Gerenciamento dos Recursos Hídricos. Estas servem como parâmetro para a sanção da Lei Estadual no 3.870 de 25 de setembro de 1997, criando o Fundo Estadual de Recursos Hídricos, sendo este destinado ao levantamento dos recursos naturais e socioeconômicos das sub-bacias hidrográficas de Sergipe (Pinto e Aguiar Netto, 2008). A criação destas implica no cumprimento do poder público em gerenciar o uso dos recursos hídricos, ordenando os limites, direitos e deveres dos seus usuários.

Segundo Aguiar Netto et al. (2013), o rio Poxim é um dos principais cursos d'água do Estado de Sergipe. Provedor principal para o abastecimento da capital do Estado, Aracaju, é ameaçado por empreendimentos urbanos e agrícolas que comprometem tanto a quantidade como a qualidade da água, com impacto direto sobre a vida cotidiana dos habitantes da região. 
Assim o sendo, tem-se como objetivo caracterizar morfometricamente a sub-bacia hidrográfica do rio Poxim-Açu, fornecendo novos subsídios para o gerenciamento dos seus recursos hídricos.

\section{MATERIAL E MÉTODOS}

\subsection{Processamento de dados}

Para o Modelo Digital de Elevação (MDE) foi utilizada a cena compatível com a escala 1:250.000 disponibilizada pela Embrapa Monitoramento por Satélite, projeto SRTM (Shuttle Radar Topography Mission), carta de articulação SC-24-Z-B.

Demais dados foram obtidos a partir do Atlas Digital dos Recursos Hídricos de Sergipe (Sergipe, 2012), processados pelas ferramentas SIG ArcGIS 10.1, com as extensões Spatial Analist e ArcHidro, e Quantum GIS 1.6.

\section{2. Área de estudo}

O rio Poxim-Açu constitui-se no principal corpo d'água da sub-bacia hidrográfica do rio Poxim. Esta, pertencente à bacia hidrográfica do rio Sergipe, encontra-se localizada entre as coordenadas $10^{\circ} 55^{\prime}$ e $10^{\circ} 48^{\prime}$ de latitude sul e $37^{\circ} 12^{\prime}$ ' e $37^{\circ} 24^{\prime}$ de longitude oeste (Figura 1), englobando, com área total ou parcialmente inclusa em sua extensão, os municípios de Aracaju, Areia Branca, Itaporanga d’Ajuda, Laranjeiras, Nossa Senhora do Socorro e São Cristóvão.

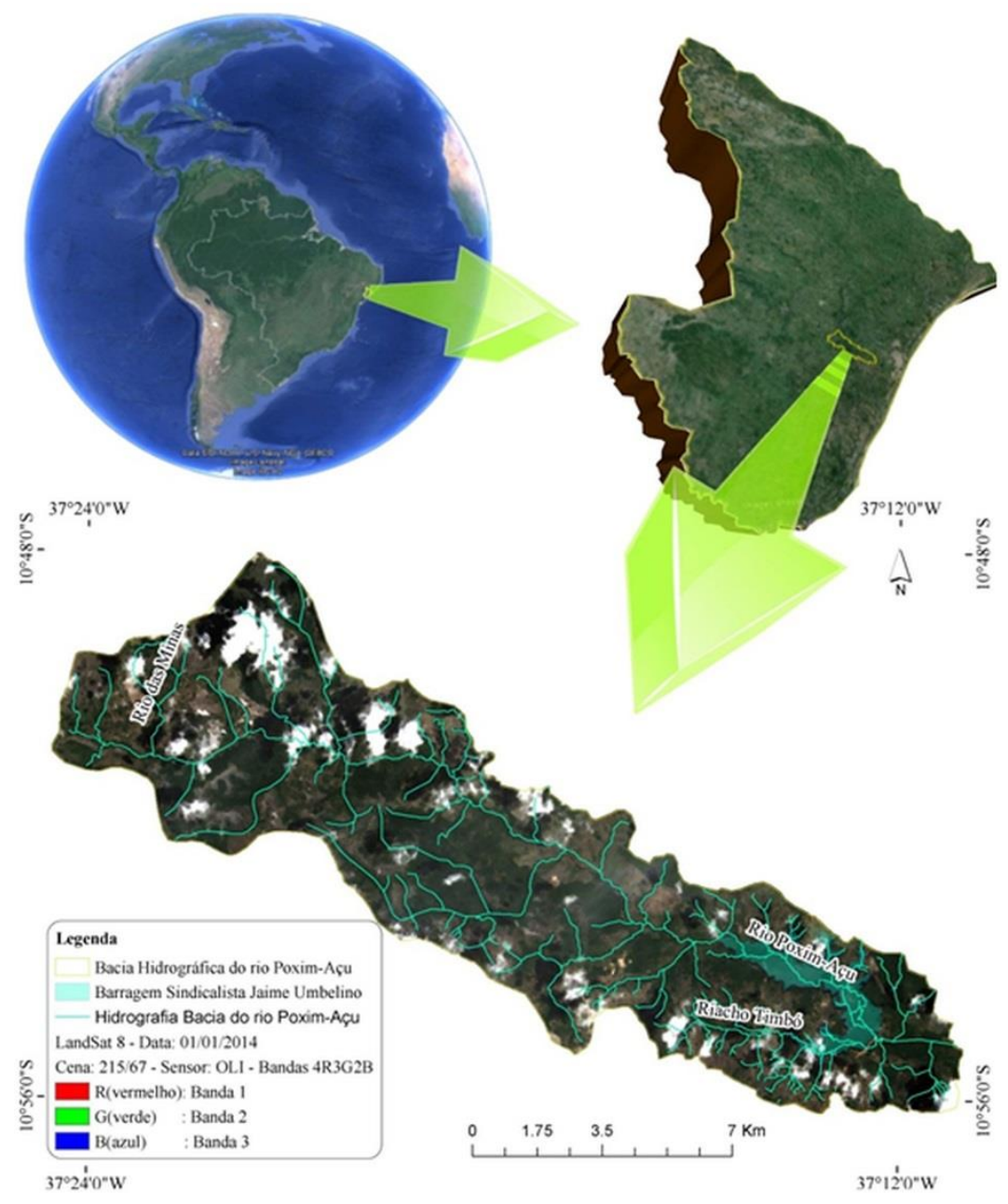

Figura 1. Localização da bacia hidrográfica do rio Poxim-Açu.

Fonte: Sergipe (2012), USGS (2014), Google Earth (2014). Adaptado pelos autores. 
Confeccionado a partir dos dados e arquivos shapes de Sergipe (2012), o mapa temático de uso e cobertura do solo (Figura 2, Tabela 1) contemplam corpos d'água, cultivos agrícolas, solos expostos, floresta estacional, mata ciliar, pastagem, povoados/distritos, vegetação de restinga, viveiro/salina e áreas degradadas.

A área de pastagem ocupa sua maior porção, com 50,30\% da bacia. A área de floresta estacional $36,56 \%$, seguido pelas áreas de cultivo agrícola/solos expostos, mata ciliar e área degradada, que representam respectivamente $6,97 \%, 3,11 \%$ e $2,31 \%$ da área em estudo. A área de povoados e distritos representa $0,16 \%$ do total. Corpos d'água e viveiros/salinas representam áreas de $0,037 \%$ e $0,0059 \%$ do total da sub-bacia. Considerando a soma das áreas englobadas por povoadas e distritos e as não mapeadas podemos considerar que a área impermeabilizada da bacia é de $0,16 \%$. Possui extensão aproximada de $26,6 \mathrm{~km}$ e uma área de $128 \mathrm{~km}^{2}$, quando delimitamos o seu exutório em um ponto localizado em seu leito nas proximidades de sua confluência com o rio Poxim-Mirim.

Tabela 1. Percentual de uso e cobertura do solo na sub-bacia do rio Poxim-Açu.

\begin{tabular}{lcc}
\hline Uso e Cobertura do Solo & Área $\left(\mathrm{km}^{2}\right)$ & $\%$ \\
\hline Pastagem & 64,40 & 50,3 \\
Floresta Estacional & 46,80 & 36,6 \\
Cultivos Agrícolas/Solos Expostos & 8,92 & 7,0 \\
Vegetação de Restinga & 3,98 & 3,1 \\
Mata Ciliar & 2,91 & 2,3 \\
Área Degradada & 0,70 & 0,6 \\
Povoado/Distritos & 0,20 & 0,2 \\
Corpos d'Água & 0,05 & 0,0 \\
Viveiro/Salina & 0,01 & 0,0 \\
Não Mapeado & 0,00 & 0,0 \\
\hline Total & $\mathbf{1 2 8 , 0 8}$ & $\mathbf{1 0 0 , 0}$ \\
\hline
\end{tabular}

Fonte: Sergipe (2012). Determinado pelos autores.

O clima da área de estudo, de acordo com a classificação climática de Köppen, enquadrase no tipo As, tropical úmido. Ocorrem cinco tipos de solos predominantes na bacia: Neossolos Quartzarênicos profundos (não hidromórficos), Neossolos Litólicos, Neossolos Litólicos Distróficos, Argissolos Vermelho Amarelo e Gleissolos (Figura 3).

A sua nascente encontra-se próximo ao povoado Cajueiro, destacando-se em sua área de entorno a produção de subsistência, com o cultivo predominante da mandioca, milho e feijão. Seu leito principal segue curso noroeste-sudeste, englobando várias propriedades rurais. No seu médio curso encontram-se médias e grandes propriedades rurais, tendo como atividade preponderante a pecuária extensiva. Na maior parte do seu curso temos margens desmatadas com regiões assoreadas. A área mais representativa de mata ciliar localiza-se a médio curso, entre o campus rural da Universidade Federal de Sergipe - UFS e o Campus São Cristovão do Instituto Federal de Sergipe - IFS. Seus principais corpos d'agua são os riachos Cajueiro, das Minas, das Serras, Porteiras, Tiririca, Caroba, Lagoa Preta, Damásio, Menino, Buraco da Besta, Sizia e Timbó, sendo este último o de maior fluxo d'água.

Considerando-se sua importância estratégica para a capital de Sergipe, em maio de 2013 suas águas foram represadas na barragem "Jaime Umbelino de Souza", localizada no povoado 
Timbó, estendendo-se por $1.125 \mathrm{~m}$, área de $5,2 \mathrm{~km}^{2}$ e capacidade de armazenamento de 32 milhões de metros cúbicos.

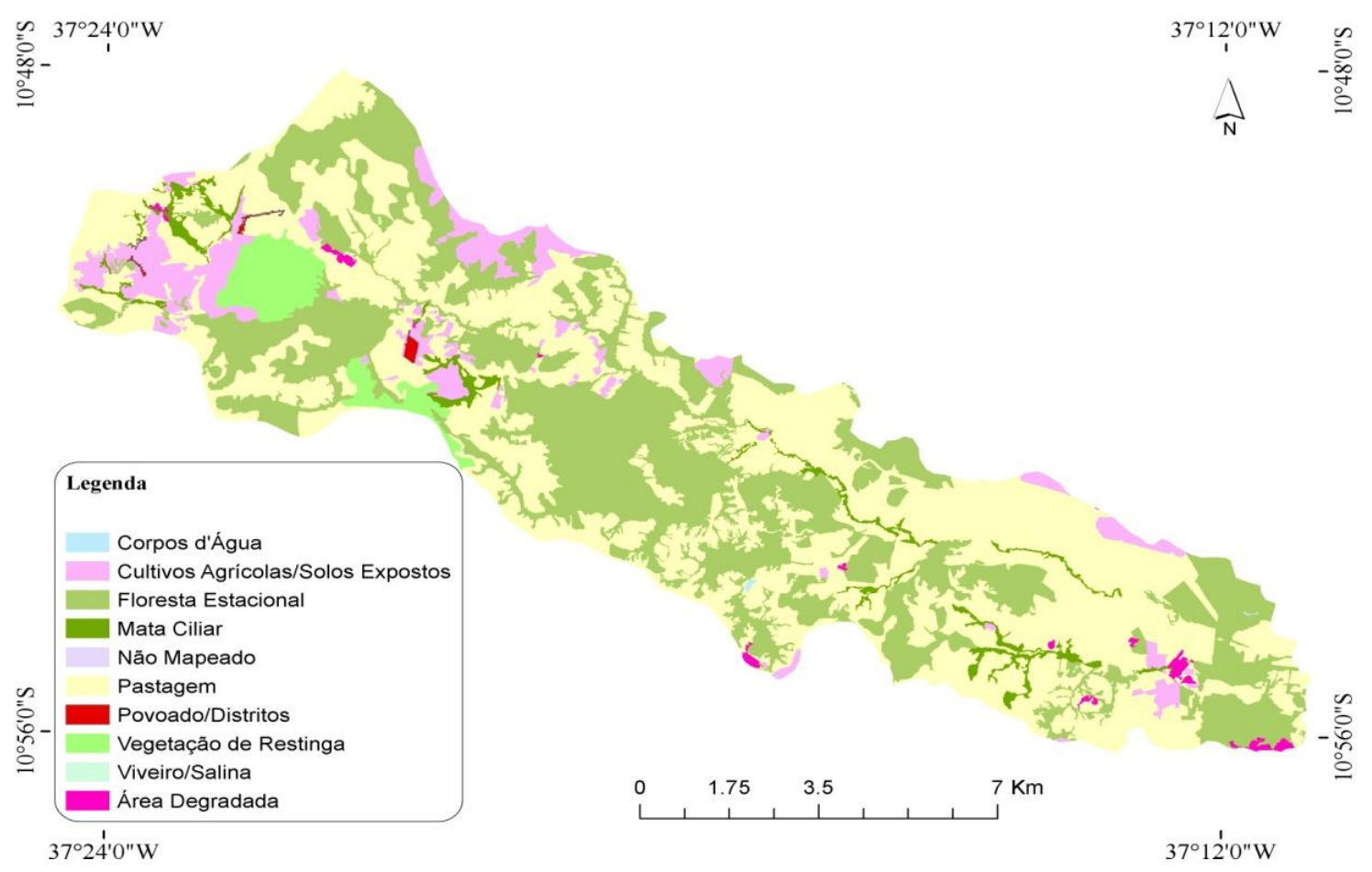

Figura 2. Mapa temático do uso e cobertura do solo da sub-bacia do rio Poxim-Açu.

Fonte: Sergipe (2012). Adaptado pelos autores.
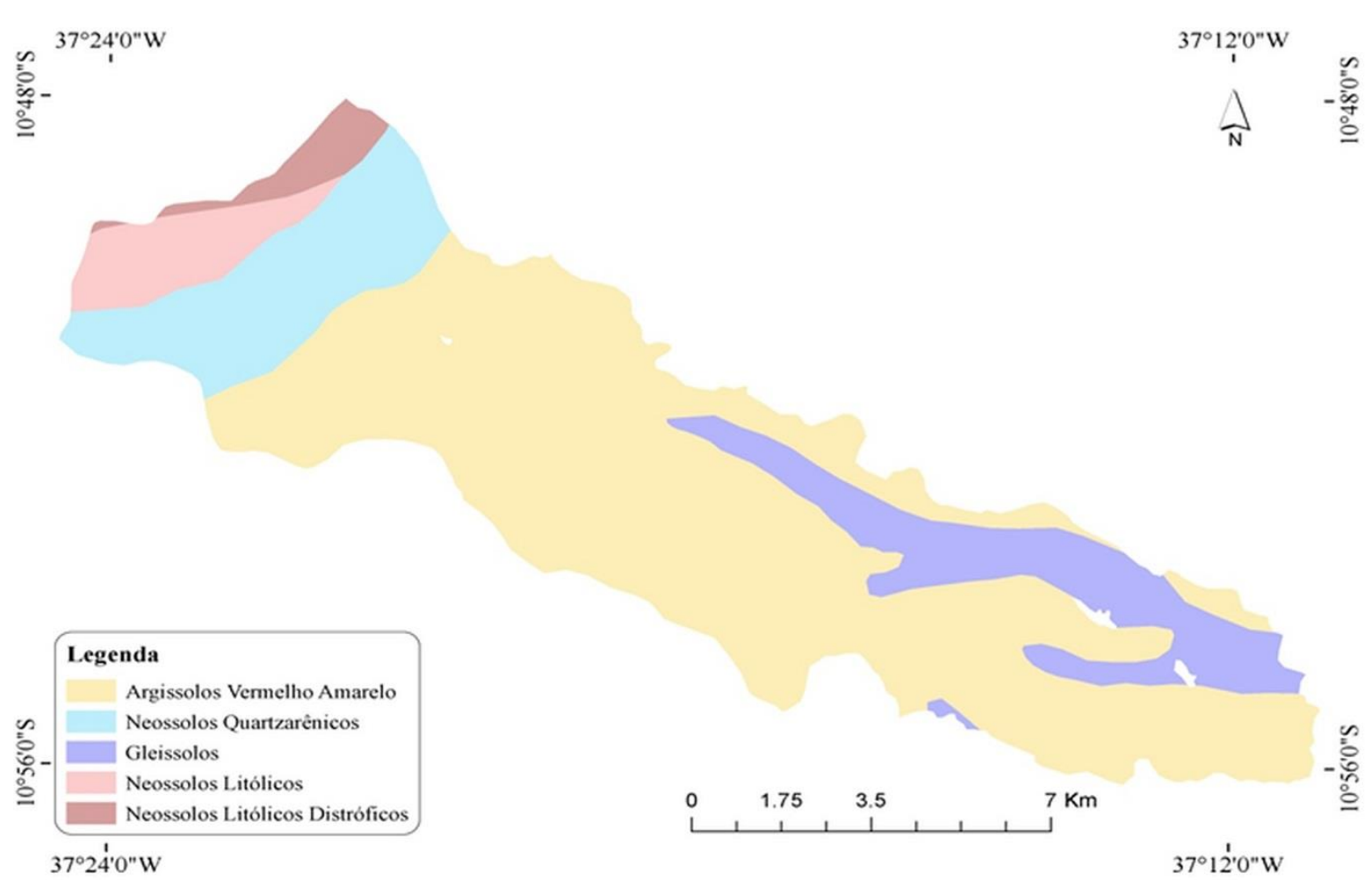

Figura 3. Tipos de solos da sub-bacia do rio Poxim-Açu.

$37^{\circ} 12^{\prime} 0^{\prime \prime} \mathrm{W}$

Fonte: Sergipe (2012). Adaptado pelos autores. 


\subsection{Variáveis morfométricas}

O levantamento dos parâmetros morfométricos foi baseado na proposta de Horton (1945), apresentada na literatura por Christofoletti $(1969,1978,1980)$ e Villela e Mattos (1975). A análise morfométrica da sub-bacia foi realizada a partir das características geométricas, de relevo e da rede de drenagem. A escolha das variáveis foi baseada nos trabalhos de Machado et al. (2011), Santos et al. (2012) e Ferrari et al. (2013), sendo as mais recorrentes:

Área da bacia (A) - representa a medida da área drenada pelo conjunto do sistema fluvial, projetada em plano horizontal, em $\mathrm{km}^{2}$. Para um bacia de maior área, maior será a complexidade do monitoramento. A área é uma variável básica para análise, associada a outras variáveis.

Comprimento total dos canais (Lt) - refere-se à soma dos comprimentos dos rios da bacia hidrográfica, em km.

Perímetro da bacia (P) - comprimento da linha imaginária ao longo do divisor de águas que delimita área da bacia hidrográfica, em km.

Comprimento do canal principal (L) - distância que se estende ao longo do curso de água da nascente principal até o exutório, em $\mathrm{km}$.

Ordem dos cursos d'água - a ordem dos cursos d'água foi determinada conforme Strahler (1957), onde os menores canais sem tributários são considerados de primeira ordem; os canais de segunda ordem surgem da confluência de dois canais de primeira ordem, e só recebem afluentes de primeira ordem; os canais de terceira ordem surgem da confluência de dois canais de segunda ordem, podendo receber afluentes de segunda e primeira ordens; os canais de quarta ordem surgem da confluência de canais de terceira ordem, podendo receber tributários de ordens inferiores, assim sucessivamente.

Densidade hidrográfica (Dr) - definido por Horton (1945) apud Christofoletti (1980), é a relação existente entre o número de rios, ou cursos de água, e a área da bacia hidrográfica. Sua finalidade é comparar a frequência ou a quantidade de cursos de água existentes em uma área de tamanho padrão (Equação 1)

$$
\operatorname{Dr}=\frac{\mathrm{N}}{\mathrm{A}}
$$

em que:

Dr representa a densidade hidrográfica,

$\mathrm{N}$ é o número de rios ou cursos de água e

A é a área da bacia em $\mathrm{km}^{2}$.

Densidade de drenagem (Dd) - correlaciona o comprimento total dos canais de escoamento com a área da bacia hidrográfica. A densidade de drenagem foi inicialmente definida por Horton (1945) apud Christofoletti (1980), podendo ser calculada pela Equação 2.

$$
\mathrm{Dd}=\frac{\mathrm{Lt}}{\mathrm{A}}
$$

em que:

Dd representa a densidade de drenagem;

Lt o comprimento total dos canais em $\mathrm{km}$; e

A, a área da bacia em $\mathrm{km}^{2}$ 
Amplitude altimétrica máxima da bacia $(\mathbf{H m})$ - corresponde à diferença altimétrica entre a altitude da desembocadura e a altitude do ponto mais alto situado em qualquer lugar da divisória topográfica. Este conceito, também denominado de "relevo máximo da bacia", considera que o ponto mais elevado da bacia deve ser a média das cotas mais elevadas, pois o seu ponto alto não compreende toda a porção mais elevada, a amplitude altimétrica, em metros, é dada pela Equação 3.

$$
\mathrm{H}_{\mathrm{m}}=\mathrm{P}_{1}-\mathrm{P}_{2}
$$

em que:

$\mathrm{H}_{\mathrm{m}}$ representa a amplitude altimétrica máxima da bacia,

$\mathrm{P}_{1}$ é o ponto mais alto e

$\mathrm{P}_{2}$ o ponto mais baixo da bacia hidrográfica

Relação de relevo da bacia $(\mathbf{R r})$ - relação entre a amplitude altimétrica máxima e a maior extensão da bacia medida paralelamente à principal linha de drenagem, a relação de relevo (Rr) é dada pela Equação 4.

$$
\operatorname{Rr}=\frac{\mathrm{Hm}}{\sqrt{\mathrm{A}}}
$$

em que:

$\mathrm{Rr}$ representa a relação de relevo da bacia,

Hm é a amplitude topográfica máxima em km e

A é a área da bacia em $\mathrm{km}^{2}$

Índice de Circularidade (IC) - o índice de circularidade, grandeza adimensional, tende para unidade à medida que a bacia aproxima-se a forma circular e diminui à medida que a forma torna-se alongada. Seu calculo é dado pela Equação 5.

$$
\mathrm{IC}=\frac{12,57 \times \mathrm{A}}{\mathrm{P}^{2}}
$$

em que:

IC é o índice de circularidade,

A é a área da bacia $\mathrm{em}^{\mathrm{km}}{ }^{2} \mathrm{e}$

P é o perímetro da bacia em $\mathrm{km}$

Índice de sinuosidade (Is) - adimensional, mede a relação entre a distância em $\mathrm{km}$ do exutório e a nascente mais distante, dado pela Equação 6.

$$
\mathrm{Is}=\frac{100(\mathrm{~L}-\mathrm{Ev})}{\mathrm{L}}
$$

em que:

Is representa o Índice de sinuosidade,

Ev é o equivalente vetorial medido em linha reta, e

L é o comprimento do canal principal em $\mathrm{km}$. 
Segundo Christofoletti (1980), o índice de sinuosidade é distribuído por classes (Tabela 2).

Tabela 2. Classes do índice de sinuosidade.

\begin{tabular}{clc}
\hline Classe & Descrição & Limites \\
\hline I & Muito reto & $>20 \%$ \\
II & Reto & $20-29 \%$ \\
III & Divagante & $30-39,9 \%$ \\
IV & Sinuoso & $40-49,9 \%$ \\
V & Muito sinuoso & $>50 \%$ \\
\hline
\end{tabular}

Fonte: Christofoletti (1980).

Coeficiente de manutenção $(\mathbf{C m})$ - esse índice tem a finalidade de fornecer a área mínima necessária para a manutenção de um metro de canal de escoamento. Christofoletti (1980) considera-o como um dos valores numéricos mais importantes para a caracterização do sistema de drenagem, podendo ser calculado através da Equação 7.

$$
\mathrm{Cm}=\frac{1}{\mathrm{Dd}} \times 1000
$$

em que:

Cm é coeficiente de manutenção e

Dd é o valor da densidade de drenagem, expresso em metros

Coeficiente de compacidade (Kc) - grandeza adimensional, varia com a forma da bacia independentemente de seu tamanho. Quanto mais irregular for a bacia, maior será o coeficiente de compacidade. Um coeficiente mínimo, igual a uma unidade (1), corresponderia a uma bacia circular; para uma bacia alongada seu valor é significativamente superior a 1 , calculado pela Equação 8, segundo Villela e Mattos (1975).

$$
\mathrm{Kc}=0,28 \frac{\mathrm{P}}{\sqrt{\mathrm{A}}}
$$

em que:

Kc representa o Coeficiente de compacidade,

P é o perímetro da bacia em $\mathrm{km}$ e

A é a área da bacia em $\mathrm{km}^{2}$

Fator de forma $(\mathbf{F})$ - relaciona a forma da bacia com a de um retângulo, correspondendo à razão entre a largura média e o comprimento axial da bacia (do exutório ao ponto mais longínquo do canal principal), podendo ser calculado através da Equação 9.

$$
\mathrm{F}=\frac{\mathrm{A}}{\mathrm{L}^{2}}
$$

em que:

$\mathrm{F}$, adimensional, é o fator de forma,

A é a área da bacia em $\mathrm{km}^{2} \mathrm{e}$

Lé o comprimento axial da bacia em $\mathrm{km}$ 
Índice de rugosidade (Ir) - o índice de rugosidade combina as qualidades de declividade e comprimento das vertentes com a densidade de drenagem, expressando-se como número adimensional dado pela Equação 10.

$$
\mathrm{I}_{\mathrm{r}}=\mathrm{H}_{\mathrm{m}} \times \mathrm{D}_{\mathrm{d}}
$$

em que:

$\mathrm{I}_{\mathrm{r}}$, representa o Índice de rugosidade,

$\mathrm{H}_{\mathrm{m}}$ é amplitude altimétrica (m) e

$\mathrm{D}_{\mathrm{d}}$ a densidade de drenagem $\left(\mathrm{m}^{-1}\right)$

A partir das variáveis supracitadas foi feita a caracterização morfométrica da sub-bacia do rio Poxim-Açu.

\section{RESULTADOS E DISCUSSÃO}

As variáveis utilizadas para caracterizar morfometricamente a sub-bacia do rio Poxim-Açu, com seus respectivos valores, são apresentadas na Tabela 3.

Tabela 3. Características morfométricas da sub-bacia do rio Poxim-Açu.

\begin{tabular}{llcc}
\hline \multicolumn{1}{c}{ Variável morfométrica } & Símbolo & Unidade & Valor \\
\hline Área da Bacia & $\mathrm{A}$ & $\mathrm{km}^{2}$ & 128,08 \\
Perímetro & $\mathrm{P}$ & $\mathrm{km}$ & 71,30 \\
Comprimento total dos canais & $\mathrm{Lt}$ & $\mathrm{km}$ & 233,27 \\
Comprimento do canal principal & $\mathrm{L}$ & $\mathrm{km}$ & 26,7 \\
Amplitude altimétrica & $\mathrm{Hm}$ & $\mathrm{m}$ & 478 \\
Coeficiente de compacidade & $\mathrm{Kc}$ & & 1,76 \\
Fator de forma & $\mathrm{F}$ & & 0,18 \\
Ordem do rio & $\mathrm{N}$ & & $44^{\mathrm{a}}$ \\
Densidade hidrográfica & $\mathrm{Dr}$ & $\mathrm{canais} / \mathrm{km}^{2}$ & 1,085 \\
Densidade de drenagem & $\mathrm{Dd}$ & $\mathrm{km} / \mathrm{km}^{2}$ & 1,82 \\
Índice de sinuosidade & $\mathrm{Is}$ & & $10 \%$ \\
Índice de Circularidade & $\mathrm{IC}$ & & 0,315 \\
Extensão do percurso superficial & $\mathrm{Eps}$ & $\mathrm{m}$ & 26,6 \\
Coeficiente de manutenção & $\mathrm{Cm}$ & $\mathrm{m}$ & 0,549 \\
Relação de relevo & $\mathrm{Rr}$ & $\mathrm{m}$ & 42,42 \\
Índice de Rugosidade & $\mathrm{Ir}$ & & 870,57 \\
\hline
\end{tabular}

A sub-bacia apresenta uma área de $128,08 \mathrm{~km}^{2}$, representando a área drenada pelo sistema pluvial inclusa entre seus divisores topográficos, projetada em plano horizontal.

O perímetro, comprimento da linha imaginária ao longo do divisor de águas, é de $71,6 \mathrm{~km}$ possuindo, conforme Strahler (1957), hierarquia fluvial de $4^{\mathrm{a}}$ ordem. A extensão do percurso superficial é de $26,6 \mathrm{~m}$, canal principal com $26,7 \mathrm{~km}$ e amplitude altimétrica de $478 \mathrm{~m}$. 
O coeficiente de compacidade é de 1,76. Esse coeficiente relaciona a forma da bacia com um círculo. Seu valor unitário corresponde a uma bacia em formato de círculo perfeito. Quanto mais irregular for a bacia, maior o valor do coeficiente de compacidade. Quanto menor o seu valor maior a tendência de haver picos de cheias. $\mathrm{O}$ valor encontrado demonstra que a sub-bacia em estudo tem pouca tendência a picos de enchentes.

$\mathrm{O}$ fator de forma calculado foi de 0,18 . O fator de forma e o coeficiente de compacidade são os parâmetros morfométricos mais utilizados para verificar se a sub-bacia é suscetível à inundação, por influenciar no tempo de concentração da bacia. O fator de forma demonstra uma relação da bacia com um retângulo e também indica a maior ou menor probabilidade de enchentes (Villela e Mattos, 1975). Na sub-bacia estudada o fator de forma encontrado é considerado baixo, indicando que esta corresponde ao formato alongado, portanto, com menor concentração do deflúvio.

A densidade hidrográfica relaciona o número de rios pela área da bacia, estabelecendo-se a quantidade de cursos d'água por $\mathrm{km}^{2}$. Sua importância é fundamental, pois deste parâmetro ocorre a representatividade do comportamento hidrográfico dentro de seus aspectos fundamentais: a magnitude da rede hidrográfica, indicando sua capacidade de gerar novos cursos d'água em função das características pedológicas, geológicas e climáticas da área (Freitas, 1952). Na bacia estudada o resultado foi 1,085 canais por quilômetro da bacia, ressaltando que existe aproximadamente um canal para cada $\mathrm{km}^{2}$ na área de estudo.

A densidade de drenagem é outro fator importante na indicação do grau de desenvolvimento do sistema de drenagem. Este índice fornece uma indicação da eficiência da drenagem da bacia, sendo expressa pela relação entre o somatório dos comprimentos dos canais da rede - sejam eles perenes intermitentes ou temporários - e a área total da bacia (Antoneli e Thomaz, 2007). Bacias com valores menores que $0,5 \mathrm{~km} / \mathrm{km}^{2}$ são consideradas com drenagem pobre. Bacias com valores da densidade de drenagem entre 0,5 e $1,5 \mathrm{~km} / \mathrm{km}^{2}$ são de drenagem regular. Valores entre 1,5 e $2,5 \mathrm{~km} / \mathrm{km}^{2}$ caracterizam uma bacia de drenagem boa, entre 2,5 e $3,5 \mathrm{~km} / \mathrm{km}^{2}$ drenagem muito e boa e, por fim, valores acima de 3,5 caracterizam bacias excepcionalmente bem drenadas (Villela e Mattos, 1975). No caso em estudo o valor da densidade de drenagem foi de $1,82 \mathrm{~km} / \mathrm{km}^{2}$, valor considerado baixo, o que nos permite classificar a bacia como de drenagem regular. Para Milani e Canali (2000), a densidade de drenagem reflete a propriedade de transmissibilidade do terreno e, consequentemente, a suscetibilidade à erosão. Carvalho et al. (2009) afirmam que valores baixos de densidade de drenagem estão geralmente associados a regiões de rochas permeáveis e de regime pluviométrico caracterizado por chuvas de baixa intensidade ou pouca concentração da precipitação.

O índice de sinuosidade representa a geometria do canal. Ele sinaliza se o canal é reto ou sinuoso. A distribuição do índice é feita em classes. Na classe I, o canal é considerado muito reto, com o valor do índice menor que $20 \%$, na classe II, o canal é considerado como reto, com valores entre 20 e $29 \%$, na classe III, classifica-se o canal como divagante, variação de 30 a 39\%, na classe IV, o canal é considerado sinuoso se a variação for de 40 a 49,95\% e finalmente a classe $\mathrm{V}$ classifica o canal como sinuoso, com valor de índice maior que $50 \%$. O índice de sinuosidade da sub-bacia em estudo foi igual a 10\%, inserindo-a na categoria canal muito reto.

$\mathrm{O}$ índice de circularidade calculado foi de 0,315 . Esse valor demonstra que a bacia não possui geometria circular. O coeficiente de manutenção da bacia foi de $0,549 \mathrm{~m}$, ressaltando o valor da área mínima necessária para a manutenção de um metro de canal de escoamento.

A relação de relevo encontrada, $42,42 \mathrm{~m}$, relaciona a amplitude altimétrica máxima da bacia e sua maior extensão medida paralelamente a principal linha de drenagem. $O$ índice de rugosidade determinado, variável que combina as qualidades de declividade e comprimento das vertentes com a densidade de drenagem, foi de 870,57. 


\section{CONCLUSÕES}

A sub-bacia hidrográfica do rio Poxim-Açu possui forma alongada, sendo praticamente reta. Em condições normais de precipitação, ou seja, excluindo-se eventos de intensidades anormais, ela é pouco susceptível a enchentes e não está sujeita a inundações.

A sub-bacia hidrográfica do rio Poxim-Açu é considerada de drenagem regular, $4^{\mathrm{a}}$ ordem, e sua densidade hidrográfica corresponde a aproximadamente um canal a cada $\mathrm{km}^{2} \mathrm{de}$ superfície.

Os dados levantados nesse estudo fornecem importantes subsídios para o planejamento e gerenciamento dos recursos hídricos do Estado de Sergipe.

\section{REFERÊNCIAS}

AGUIAR NETTO, A. O.; GARCIA, C. A. B.; HORA ALVES, J. P.; FERREIRA, R. A.; GONZAGA DA SILVA, M. Physical and chemical characteristics of water from the hydrographic basin of the Poxim River, Sergipe State, Brazil. Environmental monitoring and assessment, v. 185, n. 5, p. 4417-26, 2013. http://dx.doi.org/10.1007/s10661-012-2880-x

ANTONELI, V.; THOMAZ, E. L. Caracterização do meio físico da bacia do Arroio Boa Vista, Guamiranga-PR. Caminhos de Geografia, Uberlândia, v. 8, n. 21, p. 46-58, 2007.

CARVALHO, W. M. DE C.; VIEIRA, E. DE O.; ROCHA, J. M. J.; PEREIRA, A. K. DOS S.; CARMO, T. V. B. Caracterização fisiográfica da bacia hidrográfica do Córrego do Malheiro, no município de Sabará -MG. Revista Irriga, v. 14, n. 3, p. 398-412, 2009.

CHRISTOFOLETTI, A. A morfologia de bacias de drenagem. Notícias Geomorfológicas, Campinas, v. 18, n. 36, p. 130-142, 1978.

CHRISTOFOLETTI, A. Análise morfométrica de bacias hidrográficas. Notícias Geomorfológicas, Campinas, v. 18, n. 9, p. 35-64, 1969.

CHRISTOFOLETTI, A. Geomorfologia. São Paulo: Edgard Blücher, 1980.

FERRARI, J. L.; SILVA, S. F.; SANTOS, A. R.; GARCIA, R. F. Análise morfométrica da sub-bacia hidrográfica do córrego Horizonte Alegre, ES. Revista Brasileira de Ciências Agrárias, v. 8, n. 2, p. 181-188, 2013. http://dx.doi.org/ 10.5039/agraria.v8i2a1575

FREITAS, R. O. Textura de drenagem e sua aplicação geomorfológica. Boletim Paulista de Geografia, São Paulo, v. 11, p. 53-57, 1952.

GOOGLE EARTH. Brasil. 23/03/2014. Disponível em: https://www.google.com/maps/@ 5.6845373,-64.2535454,11848863m/data=!3m1!1e3. Acesso em: 23 mar. 2014

GUEDES, H. A. S.; SILVA, D. D. DA. Comparison between hydrographically conditioned digital elevation models in the morphometric characterization of watersheds. Engenharia Agrícola, v. 32, n. 5, p. 932-943, 2012. http://dx.doi.org/10.1590/S010069162012000500012 
HORTON, R. E. Erosinal development of streams and their drainage basin: hydrophysical approach to quantitative morphology. Geological Society of America Bulletin, v. 56, n. 3, p. 275, 1945. http://dx.doi.org/10.1130/0016-7606(1945)56[275:EDOSAT] 2.0.CO;2

IFABIYI, I. P. A reduced rank model of drainage basin response to runoff in upper Kaduna Catchment of Northern Nigeria. Global Journal of Human Social Science, v. 11, n. 6, 2011.

JAIN, V.; SINHA, R. Evaluation of geomorphic control on flood hazard through geomorphic instantaneous unit hydrograph. Current Science, v. 85, n. 11, p. 26-32, 2003.

MACHADO, R. A. S.; LOBÃO, J. S. B.; VALE, R. M. C.; SOUZA, A. P. M. J. Análise de bacias hidrográficas como suporte a definição e elaboração de indicadores para a gestão ambiental a partir do uso de geotecnologias. In: SIMPÓSIO BRASILEIRO DE SENSORIAMENTO REMOTO - SBSR, 15., 2011, Curitiba. Anais... São José dos Campos: INPE, 2011.

MAGALHAES JÚNIOR, A. P.; CORDEIRO NETTO, O. M. Ciência, cognição e informação na operacionalização da gestão participativa da água no Brasil. Sociedade e Estado, v. 18, n. 1/2, 2003. http://dx.doi.org/10.1590/S0102-69922003000100012.

MAGESH, N. S.; CHANDRASEKAR, N.; SOUNDRANAYAGAM, J. P. Morphometric evaluation of Papanasam and Manimuthar watersheds, parts of Western Ghats, Tirunelveli district, Tamil Nadu, India: a GIS approach. Environmental Earth Sciences, v. 64, n. 2, p. 373-381, 2010. http://dx.doi.org/10.1007/s12665-010-0860-4

MILANI, J. R.; CANALI, N. E. O sistema hidrográfico do rio Matinhos: uma análise morfométrica. Revista RA'EGA, n. 4, p. 139-152, 2000.

MORISAWA, M. E. Measurement of drainage basin outline form. The Journal of Geology, v. 66, n. 5, p. 587-591, 1958. http://dx.doi.org/10.1086/626538

PINTO, J. E. S. S.; AGUIAR NETTO, A. O. Clima, geografia e agrometeorologia: uma abordagem interdisciplinar. São Cristóvão: Editora UFS, 2008. 221 p.

SANTOS, A. M.; TARGA, M. S.; BATISTA, G. T.; DIAS, N. W. Análise morfométrica das sub-bacias hidrográficas Perdizes e Fojo no município de Campos do Jordão, SP, Brasil. Revista Ambiente \& Água, v. 7, n. 3, p. 195-211, 2012. http://dx.doi.org/ 10.4136/ambi-agua.945

SERGIPE. Secretaria de Estado do Meio Ambiente e dos Recursos Hídricos. Atlas digital sobre recursos hídricos. Aracajú: SEMARH, 2012. 1 DVD.

STRAHLER, A. N. Quantitative analysis of watershed geomorphology. Transactions American Geophysical Union, v. 38, n. 6, p. 913-920, 1957.

UNITED STATES. Geological Survey - USGS. EarthExplorer. Disponível em: http://earthexplorer.usgs.gov. Acesso em: 23 mar. 2014.

VASCO, A. N.; BRITTO, F. B.; PEREIRA, A. P. S.; MÉLlO JÚNIOR, A. V. M.; GARCIA, C. A. B.; NOGUEIRA, L. C. Avaliação espacial e temporal da qualidade da água na sub-bacia do rio Poxim, Sergipe, Brasil. Revista Ambiente \& Água, v. 6, n. 1, p. 118 130, 2011. http://dx.doi.org/10.4136/ambi-agua.178

VILLELA, S. M.; MATTOS, A. Hidrologia aplicada. São Paulo: McGraw-Hill, 1975. 245p. 